Susan Notohamiprodjo, Roghieh Djafarzadeh, Nicole Rieth, Monika Hofstetter, Carsten Jaeckel and Peter J. Nelson ${ }^{\mathrm{a}, \star}$

\title{
Cell surface engineering of renal cell carcinoma with glycosylphosphatidylinositol-anchored TIMP-1 blocks TGF- $\beta 1$ activation and reduces regulatory ID gene expression
}

\begin{abstract}
Tissue inhibitor of metalloproteinase 1 (TIMP1) controls matrix metalloproteinase activity through $1: 1$ stoichiometric binding. Human TIMP-1 fused to a glycosylphosphatidylinositol (GPI) anchor (TIMP-1-GPI) shifts the activity of TIMP- 1 from the extracellular matrix to the cell surface. TIMP-1-GPI treated renal cell carcinoma cells show increased apoptosis and reduced proliferation. Transcriptomic profiling and regulatory pathway mapping were used to identify the potential mechanisms driving these effects. Significant changes in the DNA binding inhibitors, TGF- $\beta 1 /$ SMAD and BMP pathways resulted from TIMP-1-GPI treatment. These events were linked to reduced TGF- $\beta 1$ signaling mediated by inhibition of proteolytic processing of latent TGF- $\beta 1$ by TIMP-1-GPI.
\end{abstract}

Keywords: DNA array; matrix metalloproteinases; pathway mapping; renal cell carcinoma; TGF- $\beta 1$ proliferation; tissue inhibitors of metalloproteinase-1 (TIMP-1).

\footnotetext{
aDedicated to Prof. Marianne Jochum, a great mentor and colleague at the University of Munich.

*Corresponding author: Peter J. Nelson, Medizinische Klinik und Poliklinik IV, Campus Innenstadt, Universität München, Arbeitsgruppe Klinische Biochemie, Schillerstrasse 42, D-80336, Münich, Deutschland, e-mail: peter.nelson@med.uni-muenchen.de Susan Notohamiprodjo: Medizinische Klinik und Poliklinik IV, Campus Innenstadt, Universität München, Arbeitsgruppe Klinische Biochemie, Schillerstrasse 42, D-80336, Münich, Deutschland Roghieh Djafarzadeh: Medizinische Klinik und Poliklinik IV, Campus Innenstadt, Universität München, Arbeitsgruppe Klinische Biochemie, Schillerstrasse 42, D-80336, Münich, Deutschland Nicole Rieth: Medizinische Klinik und Poliklinik IV, Campus Innenstadt, Universität München, Arbeitsgruppe Klinische Biochemie, Schillerstrasse 42, D-80336, Münich, Deutschland Monika Hofstetter: Medizinische Klinik und Poliklinik IV, Campus Innenstadt, Universität München, Arbeitsgruppe Klinische Biochemie, Schillerstrasse 42, D-80336, Münich, Deutschland
}

Carsten Jaeckel: Medizinische Klinik und Poliklinik IV, Campus Innenstadt, Universität München, Arbeitsgruppe Klinische Biochemie, Schillerstrasse 42, D-80336, Münich, Deutschland

Renal cell carcinoma (RCC) represents approximately $2 \%$ of all malignancies (Lipworth et al., 2006; Siegel et al., 2011). Prognosis is generally poor as the tumor is usually in late stage, with infiltration of surrounding tissue and dissemination of metastasis when symptoms occur (Koul et al., 2011; Siegel et al., 2011). Patients with RCC are generally treated with surgery, as these tumors are largely resistant to radiochemotherapy.

Matrix metalloproteinases (MMPs) are zinc-dependent endopeptidases that degrade the extracellular matrix (ECM) and play important roles in tumor progression and metastasis (Kessenbrock et al., 2010). Levels of MMP-1, -2, $-3,-9,-14,-15$ and -16 are elevated in RCC, which is thought to promote a more optimal microenvironment for tumor growth and the spread of metastasis (Catania et al., 2007).

Tissue inhibitors of metalloproteinases (TIMPs) are soluble proteins of the ECM that act as endogenous inhibitors of MMPs. TIMPs suppress MMP proteinase function in a 1:1 stoichiometric binding. The TIMP-family contains four members: TIMP-1, $-2,-3$ and -4 . In RCC, the ratio of MMPs to TIMPs is increased in favor of MMPs (Hagemann et al., 2001; Catania et al., 2007; Moore and Crocker, 2012). TIMP-1 can have diverse effects on tumor growth, including MMP-dependent growth-promoting and MMP independent effects. The MMP-dependent activities are mediated through the $\mathrm{N}$-terminal protein domain, which directly blocks MMP activity; while the MMP-independent activities are thought to be mediated through the C-terminal hemopexin-binding domain (Stetler-Stevenson, 2008; Moore and Crocker, 2012). The net effects of TIMP-1 on 
tumor biology is complex and is dependent on the concentration of protein tested and the tumor subtype studied (Stetler-Stevenson, 2008).

A recombinant protein has been developed that fuses human TIMP-1 to a glycosylphosphatidylinositol (GPI) anchor (TIMP-1-GPI). This modification effectively shifts the functional activity of TIMP-1 from the ECM directly on to the cell surface and alters proteolytic dynamics at the cell membrane (Figure 1A). Previous work has shown that TIMP-1-GPI treatment can result in enhanced biological effects (Djafarzadeh et al., 2004, 2006, 2012; Raggi et al., 2009). These include changes in cellular proliferation (Djafarzadeh et al., 2004, 2006, 2012), and in the case of RCC an increased sensitivity to Fas-mediated apoptosis, reduced proliferation, migration and capacity for invasion (Djafarzadeh et al., 2006). These effects could not be explained by changes in ECM turnover alone, but suggested additional effects on key regulatory networks controlling cell growth and cellular homeostasis. Transcriptomic profiling and pathway mapping were applied here to identify the potential downstream effects of TIMP-1-GPI treatment on RCC biology.

Recombinant TIMP-1-GPI was shown to be efficiently incorporated into the cell membrane of the RCC cell line RCC53 (Djafarzadeh et al., 2006). Treatment of RCC53 with $14 \mathrm{ng} / \mathrm{ml}$ of TIMP-1-GPI led to a strong surface signal for TIMP-1, as detected by fluorescence-activated cell sorting (FACS) using a human TIMP-1-specific antibody (Figure 1A). TIMP-1-GPI has previously been shown to enhance the association of MMPs on the surface of treated cells (Djafarzadeh et al., 2004, 2006). RCC cells treated with vehicle, $14 \mathrm{ng} / \mathrm{ml}$ rhTIMP-1 or $14 \mathrm{ng} / \mathrm{ml}$ TIMP-1-GPI, and stained with specific antibodies to MMP-1, MMP-2, MMP-7 and MMP-9 showed increased surface expression of MMP-1, MMP-2, MMP-7 and MMP-9 proteins by FACS (Figure 1A). Gelatinase zymography further validated a dose-dependent inhibition of MMP-2 and -9 secretion into the growth media of cells after treatment with TIMP-1-GPI, but not to equivalent levels of rhTIMP-1. To verify the presence of the GPI anchor, after $1 \mathrm{~h}$, TIMP-1-GPItreated cells were subjected to phospholipase $\mathrm{C}$ digestion (60 ng/ml), which cleaves GPI anchors from surface proteins. Phospholipase $\mathrm{C}$ treatment resulted in re-secretion of MMP-2 and MMP-9 into the growth media (Figure 1B).

The direct effects of TIMP-1-GPI treatment on the proliferation of RCC cells were verified using MTT [3-(4,5-dimethylthiazol-2-yl)-2,5-diphenyltetrazolium bromide] assays. RCC53 cells showed a dose-dependent suppression of TIMP-1-GPI proliferation (with a maximum at $14 \mathrm{ng} / \mathrm{ml}$ ) at 12, 48 and $72 \mathrm{~h}$ (Figure 1D). TIMP-1-GPI effects on cell apoptosis were seen in RCC53 cells using flow cytometry and annexin V-specific antibodies. Cells treated with $15 \%$ FCS, vehicle, $14 \mathrm{ng} / \mathrm{ml}$ rhTIMP-1 or $12 \mathrm{ng} / \mathrm{ml}$ TIMP-1-GPI were stained with annexin $\mathrm{V}$ fluorescein isothiocyanate (FITC) and 7-amino-actinomycin D (7-AAD) (Koopman et al., 1994). Treatment with $12 \mathrm{ng} / \mathrm{ml}$ TIMP-1-GPI resulted in a strong annexin $\mathrm{V}$ signal shift showing a two-fold increase in apoptotic cells demonstrating enhanced apoptosis in the treated cells (Figure 1C), while rhTIMP-1 treatment showed only a slight increase in apoptosis.

The molecular basis for effects linked to apoptosis and proliferation (cell cycle) were then analyzed using transcriptomic profiling and regulatory pathway mapping. RCC53 cells were treated with vehicle, $14 \mathrm{ng} / \mathrm{ml}$ rhTIMP-1, $7 \mathrm{ng} / \mathrm{ml}$ or $14 \mathrm{ng} / \mathrm{ml}$ TIMP-1-GPI. RNA was extracted after $48 \mathrm{~h}$ and was hybridized to DNA microarrays (Affymetrix Human Genome Chip HG U133 Plus2).

Robust multi-array analysis (RMA) and Genomatix Chipinspector, which use two different statistical approaches, were used to analyze the resultant CEL-files. The data were then further characterized using bioinformatics-based tools to identify pathways that were significantly influenced by TIMP-1-GPI treatment. The two independent methods applied make use of different databases and statistical methods to analyze the CEL-files (Mootha et al., 2003; Subramanian et al., 2005; Cohen et al., 2008) (Tables 1 and 2).

The results of the gene set enrichment analysis (GSEA) and Genomatix Pathway System (GePS) analyses were compared. Each output ranked the pathways showing the strongest, or most pronounced, level of regulation between the samples tested. Interestingly, both independent methods identified an overlapping set of regulatory pathways representing the highest ranked output (Tables 1 and 2). The GePS-based analysis, which incorporated both up- and down-regulated genes in the ranking, identified the inhibitor of DNA binding (ID), bone morphogenic protein (BMP), SMAD, transforming growth factor beta (TGF- $\beta$ ) and cell cycle-related pathways as being the most strongly regulated (Table 1 ). GSEA analysis ranks the up- and down-regulated sets of genes independently. The highest ranked down-regulated pathways were the BMP, TGF- $\beta$ and ID pathways. The highest ranked up-regulated genes/pathways in the GSEA analysis were cholesterol biosynthesis, and pathways linked to tRNA biosynthesis (Table 2). Based on the two methods, the TGF- $\beta 1$, BMP and DNA-binding protein inhibitor-associated pathways showed the highest association with TIMP-1-GPI-treated RCC cells (Tables 1 and 2 and Figure 2). The $I D$ genes were integrated in, or associated with, the SMAD, TGF- $\beta$ and cell cycle pathways identified and may thus be important downstream factors that are moderated through TIMP-1-GPI treatment (Tables 1 and 2). The TGF- $\beta 1$, BMP and ID-associated pathways were not found to be significantly altered 
A
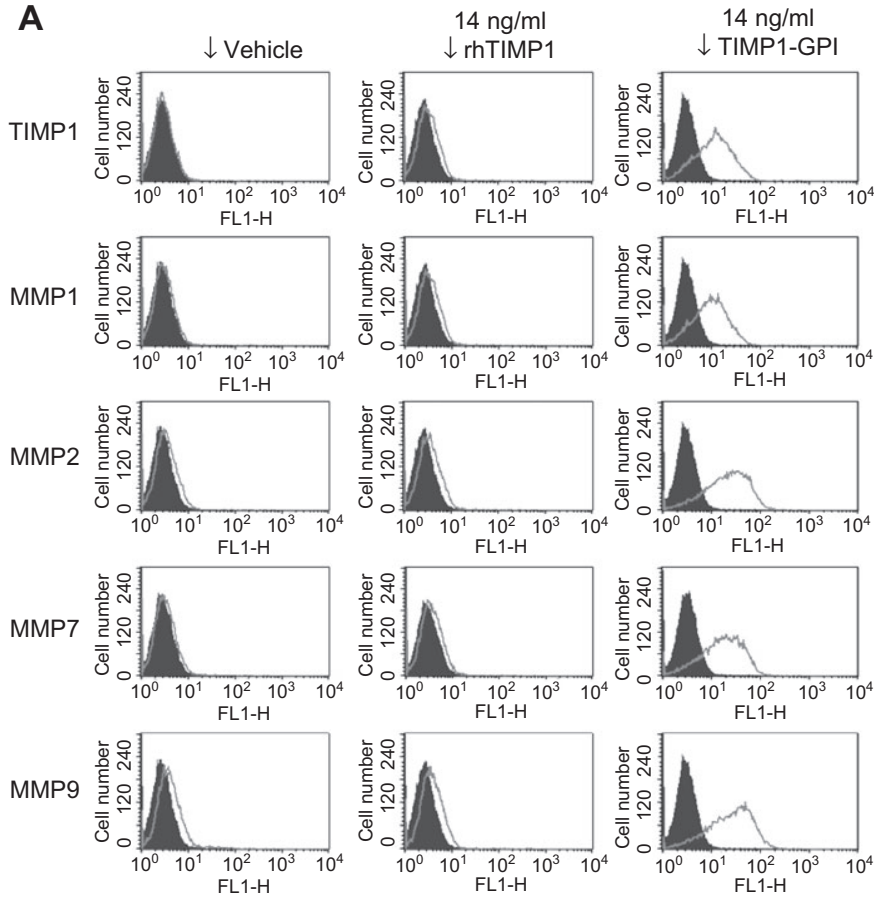

C

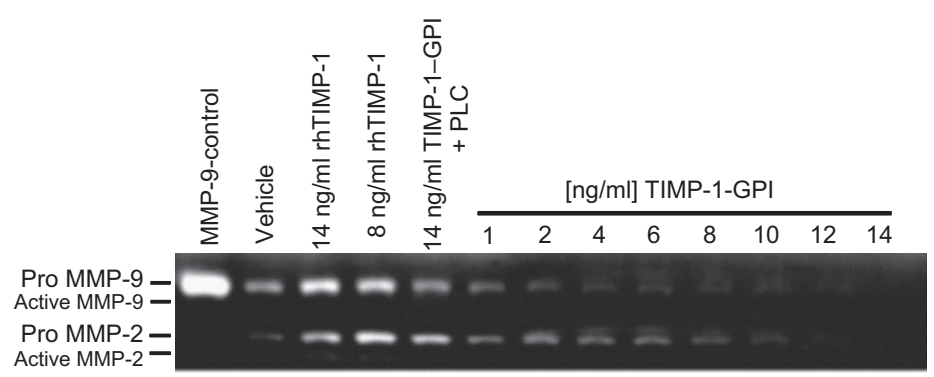

B
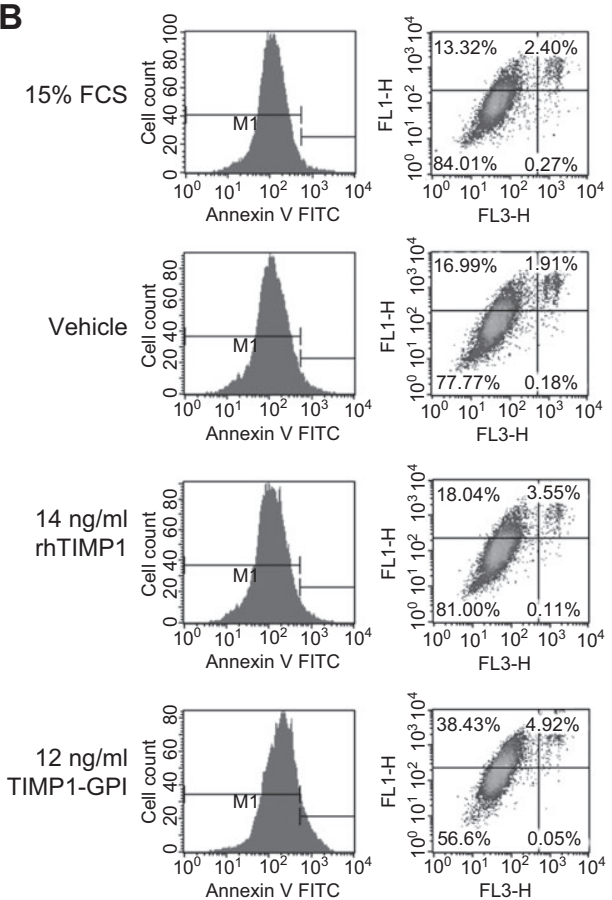

D

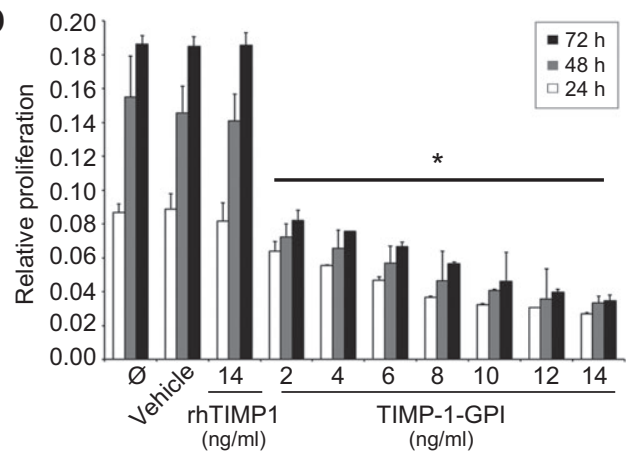

Figure 1 TIMP-1-GPI is reincorporated into the surface membranes of renal cell carcinoma (RCC) cells and modulates MMP surface expression, cellular proliferation and apoptosis.

(A) The RCC53 cell line was cultured as previously described (Djafarzadeh et al., 2006) and recombinant TIMP-1-GPI generated as detailed (Djafarzadeh et al., 2004). RCC53 cells were incubated with $14 \mathrm{ng} / \mathrm{ml}$ protein TIMP-1-GPI, rhTIMP-1 or vehicle control in serum-free RPMI 1604 medium for $2 \mathrm{~h}$ at $37^{\circ} \mathrm{C}$. The cells were washed once with $1 \times$ phosphate buffered saline (PBS), and FCS free medium was added. The cells were incubated overnight at $37^{\circ} \mathrm{C}$ and in $5 \% \mathrm{CO}_{2}$. Cell detachment was performed using Biotase (Biochrom AG, Berlin, Germany) in $1 \times$ PBS. Cells were incubated for $60 \mathrm{~min}$ on ice with specific antibodies: TIMP-1 (IM32), MMP-1 (IM35), MMP-2 (IM33), MMP-9 (IM61) (Calbiochem, Darmstadt, Germany), MMP-7 (MS 813) (Labvision, Kalamazoo, MI, USA), and IgG1 or IgG2b isoantibodies (M9269 and M8894; Sigma Aldrich, Taufkirchen, Germany). Cells were washed with $1 \times$ PBS and incubated on ice for $45 \mathrm{~min}$ with anti-mlgG-FITC secondary antibody (Dako AS, Glostrup, Denmark). Cells were then washed two times with $1 \times$ PBS and analyzed by flow cytometry (FACSCalibur, Becton Dickinson and Company, San Jose, CA, USA). Grey histograms represent isotype controls and solid-line histograms represent respective antibody stainings. (B) Binding of annexin V-fluoroisothiocyanate (FITC, FL1) and 7-AAD (FL3) was used to detect TIMP-1-GPI-mediated changes in viable, early and late apoptosis by flow cytometry (Koopman et al., 1994). Cells were incubated with $14 \mathrm{ng} / \mathrm{ml}$ protein TIMP1-GPI, rhTIMP1 or vehicle in serum free RPMI 1604 medium for $2 \mathrm{~h}$ at $37^{\circ} \mathrm{C}$ and $5 \% \mathrm{CO}_{2}$. Cells in $15 \% \mathrm{FCS}$ medium were used as controls. Detachment was performed with Biotase (Biochrom AG, Berlin, Germany). Cells were washed in 1× PBS and dispensed in $300 \mu \mathrm{l}$ Annexin binding buffer (BD Pharmingen, San Diego, CA, USA). Cells were incubated for $10 \mathrm{~min}$ at room temperature in the dark with annexin V FITC (BD Pharmingen, San Diego, CA, USA) and 7-AAD (Sigma-Aldrich, Taufkirchen, Germany; No A9400) antibodies and analyzed by FACS (see above). (C) Gelatinase zymography (Klier et al., 2001) showed reduced secretion of MMP-2 and MMP-9 with increasing levels of TIMP-1-GPI. Control phospholipase C digestion (60 ng/ml) led to re-secretion of the two gelatinase enzymes (Sigma-Aldrich, Taufkirchen, Germany; No. 661-9). (D) Renal cell carcinoma cells were treated with increasing amounts of TIMP-1-GPI $(2,4,6,8,10,12$ and $14 \mathrm{ng} / \mathrm{ml})$ and MTT assays were used to measure cellular proliferation over a 3-day period (Djafarzadeh et al., 2006). TIMP-1-GPI led to a reduction in cancer cell proliferation at 24, 48 and $72 \mathrm{~h}$. Control rhTIMP-1 at $14 \mathrm{ng} / \mathrm{ml}$, or vehicle did not influence proliferation. *Mann-Whitney $U$-test was used to compare the untreated, vehicle and rhTIMP-1 protein controls, to the TIMP-1-GPI-treated samples; a (one-tailed) $p$-value of 0.0083 was obtained for the 24-, 48- and 72-h data points. 


\begin{tabular}{|c|c|c|}
\hline Canonical pathway & $p$-Value & Genes (observed) \\
\hline \multicolumn{3}{|l|}{ GePS analysis of vehicle vs. $7 \mathrm{ng} / \mathrm{ml}$ TIMP-1-GPI } \\
\hline ID & $3.57 \mathrm{E}-04$ & ID4, ID2, ID3, RB1, ID1 \\
\hline BMP receptor signaling & $3.76 \mathrm{E}-03$ & SMAD5, PPM1A, SMAD9, SMAD7, BMPR2 \\
\hline $\begin{array}{l}\text { Mothers against DPP homolog / SMAD family } \\
\text { member } 1\end{array}$ & $2.77 \mathrm{E}-03$ & $\begin{array}{l}\text { SMAD5, HAS2, TGFBR3, PPM1A, SMAD9, THBS1, ID2, ID3, } \\
\text { SMAD7, ID1, ERBB2IP, ㅈFP1, BMPR2, TWSG1 }\end{array}$ \\
\hline TGF- $\beta$ & $3.51 \mathrm{E}-03$ & $\begin{array}{l}\text { ID4, SMAD5, HAS2, TGFBR3, PPM1A, SMAD9, THBS1, } \\
\text { MYO10, VCAN, ARL13B, ID2, ID3, FSTL1, SMAD7, ID1, } \\
\text { ERBB2IP, SYNJ2BP, BMPR2, GDF15, TWSG1 }\end{array}$ \\
\hline Cell cycle & $3.34 \mathrm{E}-05$ & $\begin{array}{l}\text { NBN, MOBKL1B, CUX1, CAV2, SAT1, PRKAR1A, ID2, ID3, } \\
\text { ATRX, KRT10, ZBTB7A, RB1, ATR, CCNE2, ID1, ZBTB2, } \\
\text { MCM10, CDT1, OTX2, FBX05 }\end{array}$ \\
\hline \multicolumn{3}{|l|}{ GePS analysis of vehicle vs. $14 \mathrm{ng} / \mathrm{ml}$ TIMP-1-GPI } \\
\hline ID & $1.27 \mathrm{E}-05$ & ID4, ID1, TCF3, ID2, ID3, PAX8 \\
\hline $\begin{array}{l}\text { Mothers against DPP homolog / SMAD family } \\
\text { member } 1\end{array}$ & $1.66 \mathrm{E}-03$ & 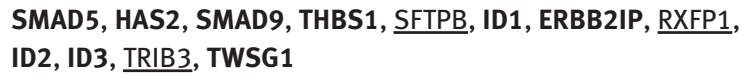 \\
\hline TGF- $\beta$ & $6.00 \mathrm{E}-03$ & 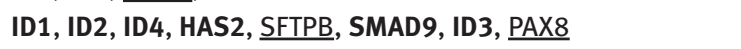 \\
\hline Cell cycle & $9.37 \mathrm{E}-04$ & $\begin{array}{l}\text { NBN, OGT, CCNE2, ID1, PRKAR1A, MCM10, CDT1, TCF3, ID2, } \\
\text { FBX05, SKP2, ID3, CASP7, IREB2 }\end{array}$ \\
\hline \multicolumn{3}{|l|}{ GePS analysis of $14 \mathrm{ng}$ rhTIMP-1 vs. $14 \mathrm{ng} / \mathrm{ml}$ TIMP-1-GPI } \\
\hline ID & $2.24 \mathrm{E}-04$ & ID1, ID4, ID2, ID3 \\
\hline $\begin{array}{l}\text { Mothers against DPP homolog / SMAD family } \\
\text { member } 1\end{array}$ & $5.07 \mathrm{E}-03$ & 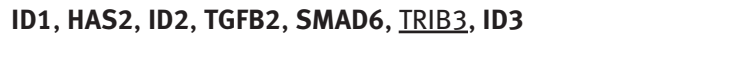 \\
\hline TGF- $\beta$ & $2.50 \mathrm{E}-03$ & ID1, ID2, ID4, HAS2, SMAD6, ID3, $\underline{\text { TRIB3 }}$ \\
\hline Cell cycle & 4.33E-03 & CCNE2, ID1, ID2, ID3 \\
\hline Proliferation & $4.61 \mathrm{E}-03$ & ID1, ID2, FGFR3, ERBB3 $, \underline{\mathrm{RHOB}}, \mathrm{CD} 74$ \\
\hline \multicolumn{3}{|l|}{ GePS analysis of vehicle vs. $14 \mathrm{ng}$ rhTIMP-1 } \\
\hline $\begin{array}{l}\text { Canonical nuclear factor kappa-light-chain-enhancer } \\
\text { of activated B cell pathway }\end{array}$ & 4.63E-03 & CYLD, RIPK2, ATM \\
\hline Epidermal growth factor receptor 1 & $5.05 \mathrm{E}-03$ & $\begin{array}{l}\text { MAP3K2, SH3BGRL, APPL1, STAT1, PRKAR1A, CREB1, } \\
\text { MAP2K7 }\end{array}$ \\
\hline $\begin{array}{l}\text { Mitogen-activated protein (MAP) kinase signaling } \\
\text { pathway }\end{array}$ & $7.02 \mathrm{E}-03$ & MAP3K2, STAT1, CREB1, MAP2K7 \\
\hline Interleukin-5 signaling pathway & $9.55 \mathrm{E}-03$ & $\underline{\text { IL5RA, STAT1 }}$ \\
\hline
\end{tabular}

Table 1 Responses of RCC53 cells to vehicle, $14 \mathrm{ng} / \mathrm{ml} \mathrm{rhTIMP-1,} 7$ or $14 \mathrm{ng} / \mathrm{ml}$ TIMP-1-GPI.

After 48 h RNA was extracted using PureLink ${ }^{T M}$ RNA Mini Kit (Invitrogen, Carlsbad, CA, USA) and the RNA concentration measured using a RNA Quant Kit (Invitrogen, Carlsbad, CA, USA). Twelve DNA microarrays (Affymetrix Human Genome Chip HG U133 Plus2) were hybridized with three replicates of each probe (vehicle, $14 \mathrm{ng} / \mathrm{ml}$ rhTIMP-1, $7 \mathrm{ng} / \mathrm{ml}$ TIMP-1-GPI, $14 \mathrm{ng} / \mathrm{ml}$ TIMP-1-GPI). For each chip, CEL-files with the measured intensities were calculated. All CEL-files underwent quality control with MADMAX Affymetrix Quality Control Pipeline (University of Wageningen, The Netherlands). The CEL-files were then analyzed using the Genomatix Chipinspector's (Genomatix GmbH, Munich, Germany) single-probe approach, which yielded an enriched gene list (FDR 0\%). This list was then analyzed using Genomatix Pathway Analysis Software, which sorts genes to individual biological pathways while assigning $p$-values based on the differentially expressed genes. The pathways then underwent nonbiased ranking based on the level of regulation detected. The pathways are presented as ranked by the software using the parameters defined above. Genes in bold were down-regulated and genes underlined were up-regulated.

in the rhTIMP-1-treated RCC cells where nuclear factor kappa-light-chain-enhancer of activated B cells, epidermal growth factor receptor 1 , mitogen-activated protein kinase and interleukin-5 pathways ranked highest. Thus, the most pronounced pathways identified with TIMP-1GPI treatment were different to those seen with rhTIMP-1 protein, suggesting unique biology associated with TIMP-1-GPI (Table 1).

The ID proteins are helix-loop-helix transcription factors thought to underlie the biology of cell cycle and apoptosis - processes strongly associated with TIMP-1-GPI treatment (Figure 1). The ID family contains four members: ID1, -2, -3 and -4 (Benezra et al., 1990; Zebedee and Hara, 2001; Perk et al., 2005; Kee, 2009). TaqMan reverse transcriptase polymerase chain reaction verified that all four ID genes were down-regulated at the steady state mRNA level in TIMP-1-GPI-treated RCC53 cells, but this was not seen with vehicle or rhTIMP-1 treatment (Figure 3A). The modulation of ID expression following TIMP-1-GPI treatment may help explain many of the effects observed. 


\begin{tabular}{|c|c|c|}
\hline Canonical pathway (Geneset) & Nominal $p$-Value & Genes \\
\hline \multicolumn{3}{|c|}{ GSEA: Down-regulated (vehicle vs. 14 ng/ml TIMP-1-GPI) } \\
\hline Signaling by BMP & 0.000 & $\begin{array}{l}\text { BMPR1A, UBE2D1, SMAD9, NOG, SMAD7, ZFYVE16, SMAD6, SMAD4, ACNR2A, } \\
\text { SKI, SMAD5, SMURF2, UBE2D3, SMAD1, ACVR2B, BMP2 }\end{array}$ \\
\hline TGF- $\beta$ signaling pathway & 0.000 & $\begin{array}{l}\text { ID2, ID4, ID3, ID1, PITX2, BMPR1A, SMAD9, EP300, NOG, SMAD7, ZFYVE16, } \\
\text { TGFB2, SMAD6, TGFBR1, AVCR1, ROCK1, IFNG, BMP8B, SMAD4 }\end{array}$ \\
\hline ID pathway & 0.003 & ID2, ID4, ID3, ID1, TCF12, RB1, MYOG, MYOD1, CCNA2, TCF3 \\
\hline \multicolumn{3}{|c|}{ GSEA: Up-regulated (vehicle vs. 14 ng/mI TIMP-1-GPI) } \\
\hline Cholesterol biosynthesis & 0.000 & IDI2, CYP51A1, GGPS1, LBR, SC4MOL, SC5DL, HMGCS1, NSDHL, HMGCR, EBP \\
\hline Cytosolic TRNA aminoacylation & 0.000 & AIMP, EEF1E1, LARS, RARS, DARS, KARS, AIMP2, IARS, NARS, TARS, FARSB, HARS \\
\hline Aminoacyl TRNA biosynthesis & 0.000 & $\begin{array}{l}\text { LARS2, MARS2, YARS2, AARS2, MTFMT, LARS, PSTK, RARS2, IARS2, TARSL2, } \\
\text { RARS, DARS }\end{array}$ \\
\hline
\end{tabular}

Table 2 Robust multichip averages for gene set enrichment analysis (GSEA) up- and down-regulated genes.

The normalized dataset was analyzed using gene set enrichment analysis (Subramanian et al., 2005), which creates a ranked list for all genes on the arrays, and then scores gene sets derived from canonical biological pathways based on this list.

High ID protein expression is found in diverse tumors including those of the prostate (Ouyang et al., 2002), breast (Schoppmann et al., 2003), colon (Wilson et al., 2001), brain (Vandeputte et al., 2002) and kidney (Li et al., 2007). The basic helix-loop-helix class of transcription factors is the target of the ID proteins (Benezra et al., 1990; Kee, 2009). The IDs strongly inhibit cell differentiation and apoptosis and enhance cell proliferation through their direct binding to these important transcription factors (Benezra et al., 1990; Kee, 2009). The down-regulation of IDs in tumors results in increased sensitivity to apoptosis and the suppression of

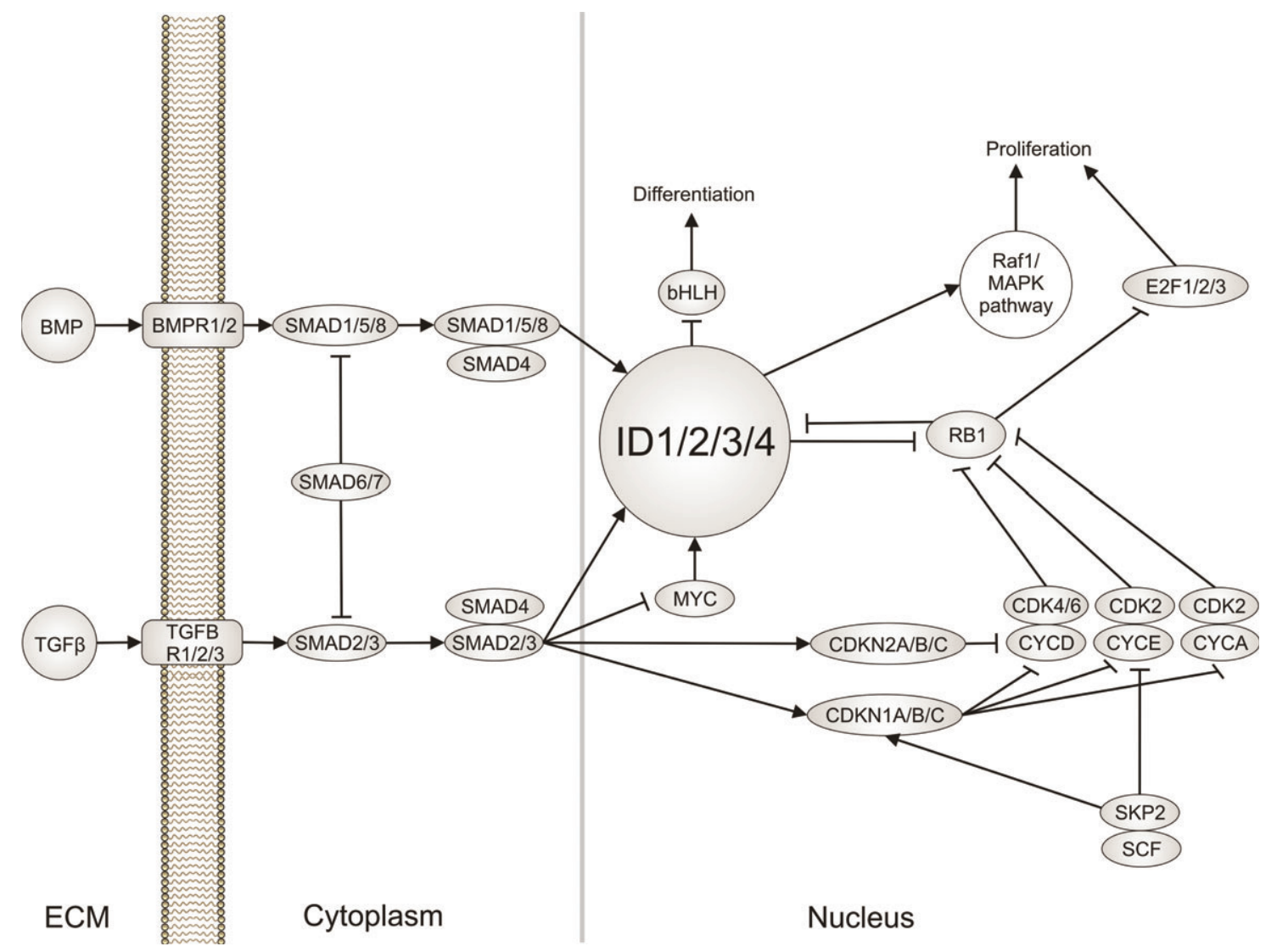

Figure 2 Transcriptomic analysis and pathway mapping of pathways altered in renal cell carcinoma cells following TIMP-1-GPI treatment. The highest ranked pathways in the analyses were linked to TGF- $\beta$ /BMP, SMAD and ID protein biology. The association of these pathways with downstream effects is presented. 
proliferation. Importantly, the ID proteins are well characterized downstream targets of TGF- $\beta 1 /$ BMP signaling (Zebedee and Hara, 2001; Perk et al., 2005). This would suggest that events upstream altering these pathways may represent an important mode of action of TIMP-1GPI in RCC cells.

Changes in TGF- $\beta 1$ may represent a potential upstream mechanism for TIMP-1-GPI. TGF- $\beta 1$ is secreted as an inactive latent protein, which is activated through
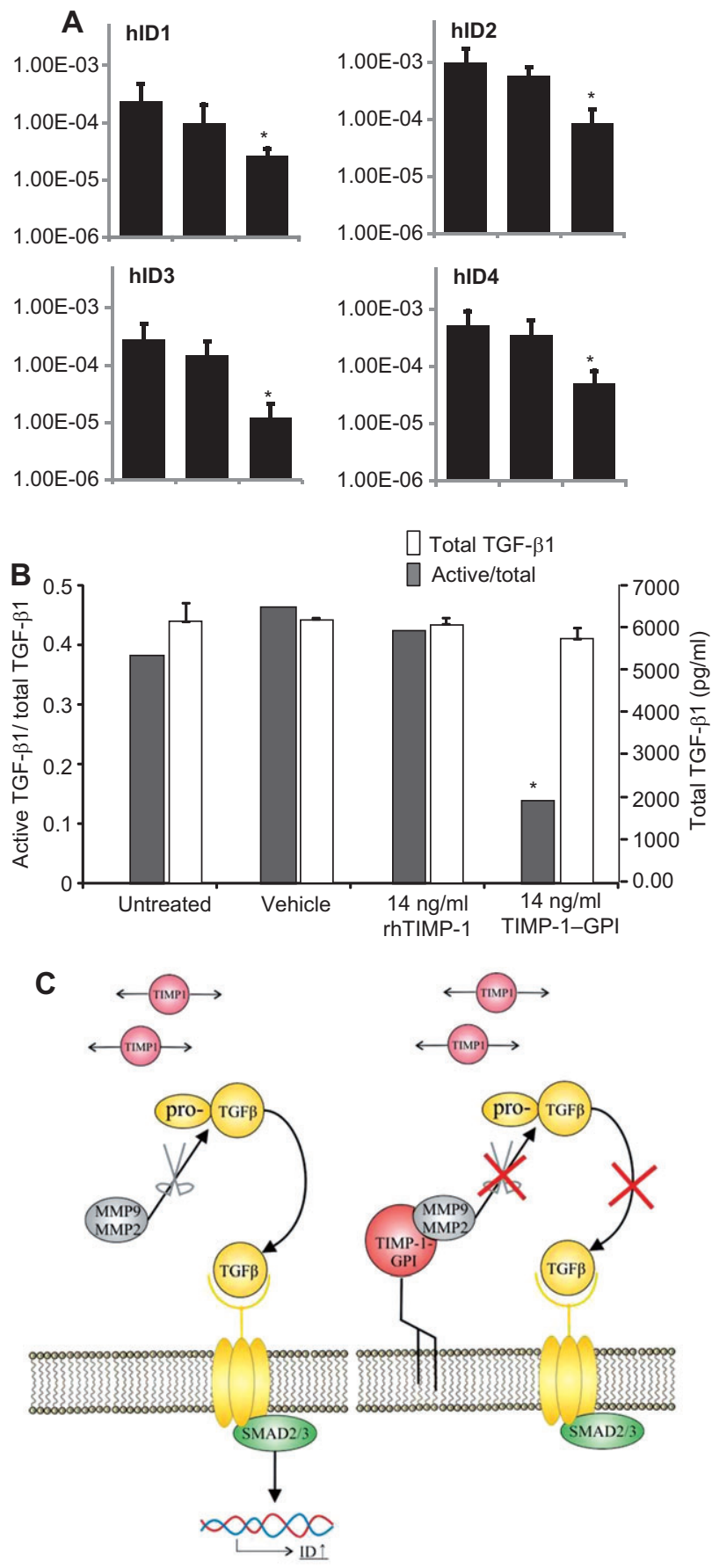

proteolytic cleavage. MMP-2 and MMP-9 can perform this processing (Yu and Stamenkovic, 2000). TGF- $\beta 1$ signaling induces downstream ID gene expression via SMAD3 (Liang et al., 2009). Altered TGF- $\beta 1$ function based on mutations leading to induction of ID regulation have been associated with several types of cancer (Padua and Massague, 2009).

This hypothesis was tested using a TGF- $\beta 1$-specific enzyme-linked immunosorbent assay that quantified the ratio of total secreted (latent/active) and TGF- $\beta 1$ protein in the growth media. The results demonstrated a profound decrease in the level of active TGF- $\beta 1$ in RCC growth media after TIMP-1-GPI treatment, but no significant change in the total amount of TGF- $\beta 1$ protein produced between vehicle, rhTIMP1 or TIMP-1-GPI-treated RCC53 cells (Figure 3B). The results suggest that TIMP-1-GPI modulation of MMP-2 and MMP-9 activity reduces TGF- $\beta 1$ processing. Reduced active TGF- $\beta 1$ would then have corresponding effects on downstream pathways, including ID gene expression.

Results from recent experiments using GPI-anchored N-terminal TIMP-1 protein that directly block MMP activity but lack the C-terminal hemopexin-binding domains, and the use of a 'null' non-MMP inhibitory mutation of TIMP-1-GPI (due to the addition of two valine residues to the amino terminus) support a central role for MMP inhibition, and not the hemopexin-binding carboxyl domain of the protein, in moderating RCC proliferation and apoptosis (Nicole Rieth, unpublished results). The blockade of TGF- $\beta 1$ processing may represent an important mode of action of TIMP-1-GPI treatment (Figure 3C).

Figure 3 TIMP-1-GPI treatment blocks TGF- $\beta 1$ processing, leading to reduced steady state expression of the ID genes.

(A) The steady-state expression of ID1, ID2, ID3 and ID4 was verified on the same samples used for the DNA arrays, as well as new samples generated in independent experiments using TaqMan (Applied Biosciences, Germany) reverse transcriptase polymerase chain reaction, as previously described (Cohen et al., 2002) for hID1 (Hs03676575_s1), hID2 (Hs00747379_m1), hID3 (Hs00171409_m1), hID4 (Hs00155465_m1) and rRNA (4310893E). *Vehicle and rhTIMP-1 protein controls were compared to the TIMP-1-GPI-treated samples using a Mann-Whitney $U$-test that yielded a (one-tailed) $p$-value of 0.067 for each of the genes examined. (B) Treatment of renal cell carcinoma cells with TIMP-1-GPI blocks the processing of latent TGF$\beta 1$ to its active form. Total and active TGF- $\beta 1$ protein concentration was measured with an enzyme-linked immunosorbent assay kit (DB Biosciences, San Jose, CA, USA, No. 559119). *Mann-Whitney U-test comparing the untreated, vehicle and rhTIMP-1 protein controls to the TIMP-1-GPI-treated samples yielded a (two-tailed) $p$-value of 0.071 and a (one-tailed) $p$-value of 0.035 . (C) Proposed effect of TIMP-1-GPI treatment on the proteolytic activation of latent TGF- $\beta 1$ through blockades of matrix metalloproteinase- 2 and -9 activity. 


\section{TIMP-1-GPI use in renal cell carcinoma treatment}

Modern treatment of RCC includes nephron-saving surgery. The tumors are resected leaving a partial kidney in place. Residual tumor missed during the initial resection can be a major complication in this procedure. TIMP1-GPI was originally developed to deliver TIMP-1 to defined tissue environments. By insertion into cell membranes, the GPI anchor limits diffusion of the fusion protein from the site of application (Djafarzadeh et al., 2004, 2006, 2012; Raggi et al., 2009). Intraoperative peritumoral application of TIMP-1-GPI as an adjuvant to surgery could help maintain tumor control by targeting microscopic residual tumor cells in the context of resection.

\section{References}

Benezra, R., Davis, R.L., Lassar, A., Tapscott, S., Thayer, M., Lockshon, D., and Weintraub, H. (1990). Id: a negative regulator of helix-loop-helix DNA binding proteins. Control of terminal myogenic differentiation. Ann. NY Acad. Sci. 599, 1-11.

Catania, J.M., Chen, G., and Parrish, A.R. (2007). Role of matrix metalloproteinases in renal pathophysiologies. Am. J. Physiol. Renal Physiol. 292, F905-911.

Cohen, C.D., Grone, H.J., Grone, E.F., Nelson, P.J., Schlondorff, D., and Kretzler, M. (2002). Laser microdissection and gene expression analysis on formaldehyde-fixed archival tissue. Kidney Int. 61, 125-132.

Cohen, C.D., Lindenmeyer, M.T., Eichinger, F., Hahn, A., Seifert, M., Moll, A.G., Schmid, H., Kiss, E., Gröne, E., Gröne, H.J., et al. (2008). Improved elucidation of biological processes linked to diabetic nephropathy by single probe-based microarray data analysis. PloS One 3, e2937.

Djafarzadeh, R., Mojaat, A., Vicente, A.B., von Luttichau, I., and Nelson, P.J. (2004). Exogenously added GPI-anchored tissue inhibitor of matrix metalloproteinase-1 (TIMP-1) displays enhanced and novel biological activities. Biol. Chem. 385, 655-663.

Djafarzadeh, R., Noessner, E., Engelmann, H., Schendel, D.J., Notohamiprodjo, M., von Luettichau, I., and Nelson, P.J. (2006). GPI-anchored TIMP-1 treatment renders renal cell carcinoma sensitive to FAS-meditated killing. Oncogene 25, 1496-1508.

Djafarzadeh, R., Sauter, S., Notohamiprodjo, S., Noessner, E., Goyal, P., Siess, W., Wörnle, M., Ribeiro, A., Himmelein, S., Sitter, T., et al. (2012). Recombinant GPI-anchored TIMP-1 stimulates growth and migration of peritoneal mesothelial cells. PloS One 7, e33963.

Hagemann, T., Gunawan, B., Schulz, M., Fuzesi, L., and Binder, C. (2001). mRNA expression of matrix metalloproteases and their inhibitors differs in subtypes of renal cell carcinomas. Eur. J. Cancer 37, 1839-1846.
TIMP-1-GPI shows unique biology when compared to equivalent concentrations of rhTIMP-1. As shown here, in the context of RCC biology, these effects can be linked to a more effective blockade of the proteolytic processing of the important tumor growth factors TGF- $\beta 1$.

Acknowledgments: The work was supported by grants from the Deutsche Forschungsgemeinschaft NE 468/2-4 to PJN. The authors would like to thank Sylke Rohrer for help with the TaqMan RT-PCR analysis. This work represents part of the doctoral thesis of S.N.

Received May 2, 2012; accepted August 20, 2012

Kee, B.L. (2009). E and ID proteins branch out. Nat. Rev. Immunol. 9, 175-184.

Kessenbrock, K., Plaks, V., and Werb, Z. (2010). Matrix metalloproteinases: regulators of the tumor microenvironment. Cell 141, 52-67.

Klier, C.M., Nelson, E.L., Cohen, C.D., Horuk, R., Schlondorff, D., and Nelson, P.J. (2001). Chemokine-induced secretion of gelatinase $B$ in primary human monocytes. Biol. Chem. 382, 1405-1410.

Koopman, G., Reutelingsperger, C.P., Kuijten, G.A., Keehnen, R.M., Pals, S.T., and van Oers, M.H. (1994). Annexin V for flow cytometric detection of phosphatidylserine expression on $B$ cells undergoing apoptosis. Blood 84, 1415-1420.

Koul, H., Huh, J.S., Rove, K.O., Crompton, L., Koul, S., Meacham, R.B., and Kim, F.J. (2011). Molecular aspects of renal cell carcinoma: a review. Am. J. Cancer Res. 1, 240-254.

Li, X., Zhang, Z., Xin, D., Chua, C.W., Wong, Y.C., Leung, S.C., Na, Y., and Wang, X. (2007). Prognostic significance of Id-1 and its association with EGFR in renal cell cancer. Histopathology 50, 484-490.

Liang, Y.Y., Brunicardi, F.C., and Lin, X. (2009). Smad3 mediates immediate early induction of Id1 by TGF- $\beta$. Cell. Res. 19 , 140-148.

Lipworth, L., Tarone, R.E., and McLaughlin, J.K. (2006). The epidemiology of renal cell carcinoma. J. Urol. 176 (6 Pt 1), 2353-2358.

Moore, C.S. and Crocker, S.J. (2012). An alternate perspective on the roles of TIMPs and MMPs in pathology. Am. J. Pathol. 180, $12-16$.

Mootha, V.K., Lindgren, C.M., Eriksson, K.F., Subramanian, A., Sihag, S., Lehar, J., Puigserver, P., Carlsson, E., Ridderstråle, M., Laurila, E., et al. (2003). PGC-1alpha-responsive genes involved in oxidative phosphorylation are coordinately downregulated in human diabetes. Nat. Genet. 34, 267-273. 
Ouyang, X.S., Wang, X., Lee, D.T., Tsao, S.W., and Wong, Y.C. (2002). Over expression of ID-1 in prostate cancer. J. Urol. 167, 2598-2602.

Padua, D. and Massague, J. (2009). Roles of TGFbeta in metastasis. Cell. Res. 19, 89-102.

Perk, J., lavarone, A., and Benezra, R. (2005). Id family of helix-loophelix proteins in cancer. Nat. Rev. Cancer 5, 603-614.

Raggi, M.C., Djafarzadeh, R., Muenchmeier, N., Hofstetter, M., Jahn, B., Rieth, N., and Nelson, P.J. (2009). Peritumoral administration of GPI-anchored TIMP-1 inhibits colon carcinoma growth in Rag-2 gamma chain-deficient mice. Biol. Chem. 390, 893-897.

Schoppmann, S.F., Schindl, M., Bayer, G., Aumayr, K., Dienes, J., Horvat, R., Rudas, M., Gnant, M., Jakesz, R., and Birner, P. (2003). Overexpression of Id-1 is associated with poor clinical outcome in node negative breast cancer. Int. J. Cancer 104, 677-682

Siegel, R., Ward, E., Brawley, O., and Jemal, A. (2011). Cancer statistics, 2011: the impact of eliminating socioeconomic and racial disparities on premature cancer deaths. CA Cancer J Clin 61, 212-236.

Stetler-Stevenson, W. (2008). Tissue inhibitors of metalloproteinases in cell signaling: metalloproteinase-independent biological activities. Sci. Signal 1, re6.
Subramanian, A., Tamayo, P., Mootha, V.K., Mukherjee, S., Ebert, B.L., Gillette, M.A., Paulovich, A., Pomeroy, S.L., Golub, T.R., Lander, E.S., et al. (2005). Gene set enrichment analysis: a knowledge-based approach for interpreting genome-wide expression profiles. Proc. Natl. Acad. Sci. USA 102, 15545-15550.

Vandeputte, D.A., Troost, D., Leenstra, S., ljlst-Keizers, H., Ramkema, M., Bosch, D.A., Baas, F., Das, N.K., and Aronica, E. (2002). Expression and distribution of id helix-loop-helix proteins in human astrocytic tumors. Glia 38 , 329-338.

Wilson, J.W., Deed, R.W., Inoue, T., Balzi, M., Becciolini, A., Faraoni, P., Potten, C.S., and Norton, J.D. (2001). Expression of Id helixloop-helix proteins in colorectal adenocarcinoma correlates with p53 expression and mitotic index. Cancer Res. 61, 8803-8810.

Yu, Q. and Stamenkovic, I. (2000). Cell surface-localized matrix metalloproteinase-9 proteolytically activates TGF-beta and promotes tumor invasion and angiogenesis. Genes Dev. 14, 163-176.

Zebedee, Z. and Hara, E. (2001). Id proteins in cell cycle control and cellular senescence. Oncogene 20, 8317-8325. 